\title{
Multi Objective Optimization for Transmission Network Expansion Planning using Modified Bacterial Foraging Technique
}

\author{
S.Jaganathan \\ Assistant Professor, \\ Electrical Engineering, \\ Dr.S.Palaniswami \\ Professor, \\ Electrical Engineering, \\ C.Sasi Kumar \\ RVS College of Engg and Tech, Government College of Tech, RVS College of Engg and Tech, \\ Coimbatore, Tamilnadu, India. Coimbatore, Tamilnadu, India. Coimbatore, Tamilnadu, India
}

\begin{abstract}
Multi-objective optimisation is a proven well known parameter tuning technique in complex power system problems. It is especially suited to solve complex transmission network expansion planning. This paper proposes a practical method for transmission network expansion planning by bacterial foraging technique. The electricity industry has always been interested in expanding investment in the transmission sector of the industry. As load demand increases and generation expands to meet the need, transmission expansion becomes important in order to increase social welfare by reducing total system operating cost, and to make the system more reliable. In this context, two objectives: investment cost and network adequacy restrictions are considered to overcome the drawbacks of conventional mathematical optimization method in arriving at local optimum and dimension disasters, we introduced the bacterial foraging technique into transmission network optimal planning for the first time, from which the optimal scheme is generated. The bacterial foraging is used as the optimization tool to obtain the Pareto approximation set solutions. The proposed algorithm is implemented on typical IEEE 6 bus systems and performance is assessed by statistical test.
\end{abstract}

General terms:

Algorithm, Performance, Verification.

\section{Keywords:}

TNEP, multi-objective optimization (MOP), network adequacy restrictions, operational cost, bacterial foraging.

\section{INTRODUCTION}

Multiple objectives are often considered simultaneously in practical transmission network expansion planning [1][2][5]. Optimization is a procedure of finding and comparing feasible solutions until a better solution can be found. Most of the real world problems involve than one objective, making the multiple conflicting objectives to solve. As the real world problems involve simulation and optimization of multiple objectives, results and solutions of these problems which are different from single objective problem [4][11][19]. In multi objective optimization, there may not exist a solution that is best with respect to all objectives. Transmission network expansion planning (TNEP) is one of the important decisionmaking activities in electric utilities. It determines the characteristic and future electric power network [12][13]. The planner has to estimate the most economic network which feeds the loads with the required degree of quality and to minimize construction and operational cost, while meeting technical and reliability constrains [3-5].TNEP should be satisfy the required adequacy of lines for delivering safe and reliable electric power to load centre However bacterial foraging can find multiple solutions[2] [14] in one single simulation run due to their population based search based approach. Thus bacterial foraging is ideally suited for multi-objective optimization problems [18][19]. The earliest method to solve a multi-objective optimizer is to ignore one objective. The work focuses on applying the theory of Multi-Objective Optimization to the problem of Transmission expansion planning. Multi-objective optimization works appropriately for optimizing objectives with conflicting, non-conflicting, or uncertain relationships. It is also flexible and deals with objectives that are not commensurate. A deterministic approach is used to solve the multi-objective mixed-integer nonlinear Optimization numerical problem.

Transmission expansion planning is not a new area in power systems; it has always been a challenging subject of interest that evolves with time. Papers that consider only investment/construction cost as an objective are: The simulated annealing (SA) [10], method has been successfully applied to large-scale TNEP problem. The SA [12] tries to avoid local optima by allowing temporary, limited deterioration of actual solutions. The genetic algorithm (GA) [1][9] method is another type of newly adopted optimization approaches for the solution of the TNEP problem. GA [11][20] is based on the mechanics of evolution and natural genetics. With the development of artificial intelligence [22](AI) theory and techniques, some new AI-based approaches to the transmission network optimal planning problem have been proposed in recent years, such as the expert system based and the artificial neural network (ANN) based methods. A recent paper on transmission network expansion planning, presented in the Power Engineering Society in San Francisco (June 2009), does not consider the full AC network model, power system operation 
cost, or network constraints. Thus the evolutionary algorithms (EAs) cannot guarantee the optimality of the solutions; they are shown to be efficient in providing suboptimal solutions for various problems. Objectives for transmission expansion planning are often conflicting and the need for multi-objective optimization is important for decision-making purposes. All of the papers found in 1985-2009 treat the transmission expansion planning problem as a single-objective optimization, and objectives other than investment cost and/or operation cost are rarely mentioned.

The problem of transmission expansion in power system is modelled as a multi-objective programming problem. The multi-objective bacterial foraging technique approach is used to minimize the single-objective and multi-objective functions. The proposed model decides the capacity and location of the new facilities as well as the imported power from the grid through the main substation by minimizing two functions related to the total expansion cost and minimizes network adequacy restrictions.

\section{PROBLEM FORMULATION}

The main objectives are minimization of installation cost of new facilities, minimization of system operational (maintenance and lost energy) cost, and enhancement of system reliability.

\subsection{Objective Functions}

The former (objective-1) deals with minimization of network adequacy restrictions. The latter (objective- 2) is optimized by minimizing total cost.

\subsubsection{Network Adequacy Restriction}

The transmission network is a mixed integer non-linear. The TNEP problem is a mixed integer non-linear optimization problem. Due to consider the proposed objective function is defined as

$$
\text { Fitness }=\sum_{i, j=\Omega} C L_{\mathrm{ij}} \mathrm{n}_{\mathrm{ij}} \mathrm{C}_{\mathrm{Aw}} *\left(\mathrm{~T}-\mathrm{T}_{\mathrm{o}}\right)^{2}
$$

Where

$\mathrm{CL}_{\mathrm{ij}}=$ construction cost o each line in branch $\mathrm{i}-\mathrm{j}$.

$\mathrm{N}_{\mathrm{ij}}=$ number of new circuits in corridor $\mathrm{i}-\mathrm{j}$.

$\Omega=$ set of all corridors.

$\mathrm{C}_{\mathrm{AW}}=$ annual worth of transmission network adequacy.

$\mathrm{T}_{\mathrm{o}}=$ required time for missing the expanded network adequacy

$\mathrm{T}=$ required time for missing the expanded network which is calculated by bacterial foraging.

\subsubsection{Minimization Operational Cost}

$$
\begin{aligned}
\text { Min }= & \sum_{i, j=\Omega} C_{\mathrm{ij}} \mathrm{n}_{\mathrm{ij}}+\alpha_{\mathrm{i}} \sum r_{\mathrm{i}} \delta_{\mathrm{i}} \sum d_{\mathrm{i}} \\
\text { Where } & \\
\mathrm{C}_{\mathrm{ij}}= & \text { cost of circuit } \mathrm{i}-\mathrm{j} . \\
\mathrm{n}_{\mathrm{ij}}= & \text { number of added circuits } \\
\mathrm{d}_{\mathrm{i}}= & \text { demand in bus } \mathrm{i} . \\
\mathrm{r}= & \text { load shedding vector } \\
\alpha_{\mathrm{i}}, \delta_{\mathrm{i}}= & \text { factors that transform load shedding and } \\
& \quad \text { demand in financial values }
\end{aligned}
$$

\subsection{Constraints}

Several restrictions have to be modelled in a mathematical solutions are in line with planning requirements. Thus the constrain of the problem is

$$
\begin{gathered}
\text { Sf+g-d }=0 \\
\mathrm{f}_{\mathrm{ij}}-\mathrm{R}_{\mathrm{ij}}\left(\mathrm{n}_{\mathrm{ij}}{ }^{0}+\mathrm{n}_{\mathrm{ij}}\right)\left(\theta_{\mathrm{i}}-\theta_{\mathrm{j}}\right)=0
\end{gathered}
$$

Where

$\mathrm{S}=$ branch node incidence matrix of the power system.

$\mathrm{f}=$ active power matrix in each corridor

$\mathrm{g}=$ generation vector

$\mathrm{d}=$ demand vector

$\theta_{\mathrm{ij}}=$ phase angle in bus $\mathrm{i}$ and bus $\mathrm{j}$.

$\mathrm{f}_{\mathrm{ij}}=$ power flow

$R_{i j}=$ susceptance of circuit $i-j$

$\mathrm{n}_{\mathrm{ij}}{ }^{0}=$ number of initial circuits in corridor $\mathrm{i}-\mathrm{j}$

$\mathrm{n}_{\mathrm{ij}}=$ number of added circuits

In this, the objective function is different and the goal is to obtain the number of required circuits for adding to the existed network along the specific planning horizon. For the solution of this problem, there are various methods such as classic mathematical and heuristic methods. But for our work solving this TNEP problem, bacterial foraging technique is used to optimize and for implementation.

\section{MULTI-OBJECTIVE OPTIMIZATION PROBLEMS}

Multiple objective problems are solved using a variety of different approaches [18][19]. Often the multi-objective is combined into a single objective so that optimization and mathematical methods can be used. In general, for a problem with $\mathrm{n}$ objective functions, the multi-objective formulation can be as follows

Minimize/maximize $f_{i}(x)$ for $i=1,2,3 \ldots n$

Subject to

$$
\begin{array}{ll}
G_{j}(x) \leq 0 & j=1,2 \ldots J \\
H_{k}(x)=0 & k=1,2 \ldots K
\end{array}
$$

There are $n$ objectives and $p$ variables so $f(x)$ is an $n$ dimensional vector and $\mathrm{x}$ is a $\mathrm{p}$ dimensional vector corresponding to $\mathrm{p}$ decisions or variables, solutions to a multi-objective optimization problem are often mathematically expressed in terms of nondominated or superior points.

We say in maximization problem that $\mathrm{x}$ dominates $\mathrm{y}$ if

$$
\begin{aligned}
& \mathrm{f}_{\mathrm{i}}(\mathrm{x}) \geq \mathrm{f}_{\mathrm{i}}(\mathrm{y}) \forall \mathrm{i} \text { and } \mathrm{f}_{\mathrm{i}}(\mathrm{x})>\mathrm{f}_{\mathrm{i}}(\mathrm{y}) \\
& \text { for at least one } \mathrm{i} i \in\{1,2 \ldots \mathrm{n}\} ;
\end{aligned}
$$

Similarly, for a minimization problem dominates $y$ if

$$
\mathrm{f}_{\mathrm{i}}(\mathrm{x}) \leq \mathrm{f}_{\mathrm{i}}(\mathrm{y}) \quad \forall \mathrm{i}_{\text {ind }} \mathrm{f}_{\mathrm{i}}(\mathrm{x})<\mathrm{f}_{\mathrm{i}}(\mathrm{y})
$$

$\mathrm{X}$ is defined as the set of feasible solutions or feasible decision alternatives. Thus, in a maximization problem $\mathrm{x}$ is non-dominated in X.Then the optimal solutions to a multi objective optimization problem are in the set of non dominated solutions $\mathrm{N}$ [13][14], and they are usually known as pareto optimal set. Generally the two most common approaches to solve multiple objectives are: combine them into a single objective function and obtain a single solution, obtain set of 
non-dominated Pareto optimal solutions. Thus there is a need to bridge the gap between single solutions and Pareto optimal sets.

The Pareto set includes all rational choices, among which the decision maker has to select the final solution by trading the objectives against each other. The search is then not for one optimal solution but for a set of solution that are optimal in a border sense. There are a number of techniques to search the solution for Pareto optimal solutions. The objective of this search is to achieve this balance, by introducing two practical methods that reduce the Pareto optimal set to achieve a smaller set called the "pruned pareto set".

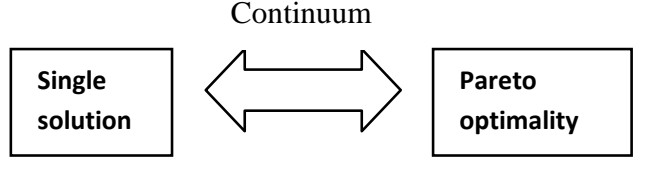

\section{BACTERIAL FORAGING}

The bacterial foraging technique which is tailored for optimizing difficult numerical functions and based on metaphor of human social interaction. Its paradigm be implemented in simple in simple form of computer codes and is computationally inexpensive in terms of both memory and speed. Vectors are taken as presentation of particle since most optimization problems are convenient for such variable presentations.

Nowadays Bacteria Foraging technique is gaining importance in the optimization problems. Because search strategy of bacteria is salutary (like common fish) in nature and Bacteria can sense, decide and act so adopts social foraging (foraging in groups). A group of bacteria move in search of food and away from noxious elements - a biological method known as foraging [16]. All bacteria try to move upward the food concentration gradient individually. At the initial location they measure the food concentration and then tumble to take a random direction and swim for a fixed distance and measure the concentration there. This tumble and swim make one chemo tactic step. If the concentration is greater at next location then they take another step in that direction [10][11][12]. When concentration at next location is lesser that of previous location they tumble to find another direction and swim in this new direction. This process is carried out up to a certain number of steps, which is limited by the lifetime of the bacteria. At the end of its lifetime the bacteria that have gathered good health that are in better concentration region divide into two cells. Thus in the next reproductive step the next generation of bacteria start from a healthy position. The better half reproduces to generate next generation where as the worse half dies. This reproduction step is also carried out a fixed number of times. In the optimization technique we can take the variable we want to optimize as the location of bacteria in the search plane (the plane where the bacteria can move).The specifications such as number of reproductive steps, number chemo tactic steps which are consisted of run (or swim) and tumble, swim length, maximum allowable swims in a particular direction [18][19][20]are given for a particular problem then the variable can be optimized using this Bacteria Foraging Optimization technique.

\section{ALGORITHM}

Step 1 : Initialize parameters n, N, NC, Ns, Nre, Ned, Ped,C(i)

$$
(\mathrm{i}=1,2, \ldots . \mathrm{N}), \emptyset \mathrm{i}
$$

Where,

$$
\mathrm{n} \text { : dimension of the search space }
$$

$\mathrm{N}$ : the number of bacteria in the population.

$\mathrm{N}_{\mathrm{c}}$ : chemotactic steps.

$\mathrm{N}_{\mathrm{re}}$ : the number of reproduction steps

$\mathrm{N}_{\mathrm{ed}}$ : the number of elimination dispersal events

$\mathrm{P}_{\mathrm{ed}}$ : elimination dispersal with probability.

C(i) : the size of the step taken in the random direction specified by the tumble.

Step 2: Elimination-dispersal loop: $1=1+1$.

Step 3: Reproduction loop: $\mathrm{k}=\mathrm{k}+1$.

Step 4: Chemo taxis loop: $\mathrm{j}=\mathrm{j}+1$.

Sub step a: For $\mathrm{i}=1,2, \ldots, \mathrm{N}$, take a chemo tactic step for bacterium i as follows.

Sub step b: Compute fitness function ITSE (i; j; k; 1$)$

Sub step c: Let ITSE $_{\text {last }}=\operatorname{ITSE}_{(\mathrm{i}, j \mathrm{j} ; \mathrm{k} ; \mathrm{l})}$ to save this value since we may find a better cost via a run

Sub step d: Tumble: generate a random vector $\Delta(i) \in R^{\mathrm{n}}$ with each element $\Delta_{m}(i), m=1,2, \ldots, p$, a.

Sub step e: Move: Let,

$$
\emptyset^{x}(i+1, j, k)=\emptyset^{x}(i, j, k)+c(i) \frac{\Delta(i)}{\sqrt{\Delta^{T}(i) \Delta(i)}}
$$

This results in a step of size C(i) in the direction of the tumble for bacterium $\mathrm{i}$.

Sub step f: Compute ITSE (i,j+1,k,l).

Sub step g: Swim.

i. Let $\mathrm{m}=0$ (counter for swim length).

ii. While $\mathrm{m}<\mathrm{Ns}$ (if have not climbed down too long).

iii. Let $\mathrm{m}=\mathrm{m}+1$.If $\left(\operatorname{ITSE}_{(\mathrm{i}, \mathrm{j}+1, \mathrm{k}, \mathrm{l})}<\mathrm{ITSE}_{\text {last }}\right.$ ( if doing better),

iv) let ITSElast $=\operatorname{ITSE}(\mathrm{i}, \mathrm{j}+1, \mathrm{k}, \mathrm{l})$ and let,

$\emptyset^{x}(i+1, j, k)=\emptyset^{x}(i+1, j, k)+c(i) \frac{\Delta(i)}{\sqrt{\Delta^{T}(i) \Delta(i)}}$

v) Else, let $\mathrm{m}=\mathrm{Ns}$. This is the end of the while statement.

Sub step h: Go to next bacterium $(i, 1)$ if $i \neq N$ (i.e., go to [sub step b] to process the next bacterium.

Step 5: If $\mathrm{j}<\mathrm{N}_{\mathrm{c}}$, go to step 3. In this case, continue chemo taxis, since the life of the bacteria is not over.

Step 6: Reproduction:

Sub step a: For the given $k$ and 1 , and for each $i=1,2, \ldots, N$, let

$$
\operatorname{ISTE}_{\text {health }}^{\mathrm{i}}=\sum_{j=1}^{N_{c}+1} \operatorname{ISTE}(i, j, k, l)
$$

the health of the bacterium i (a measure of many nutrients it got over its lifetime and how successful it was at avoiding noxious substances). 


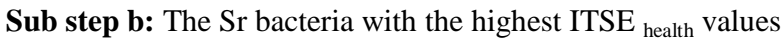
die and the remaining $\mathrm{Sr}$ bacteria with the best values split (this process is performed by the copies that are made are placed at the same location as their parent).

Step 7: If $k<$ Nre, go to [step 3]. In this case, we have not reached the number of specified reproduction steps, so we start the next generation of the chemotactic loop.

Step 8: Elimination-dispersal: For $i=1,2, \ldots \ldots, \mathrm{N}$, with probability Ped, eliminate and disperse each bacterium, which results in keeping the number of bacteria in the population constant. To do this, if a bacterium is eliminated, simply disperse one to a random location on the optimization domain. If $1<\mathrm{Ned}$, then go to [step 2]; otherwise end.

\section{FLOWCHART}

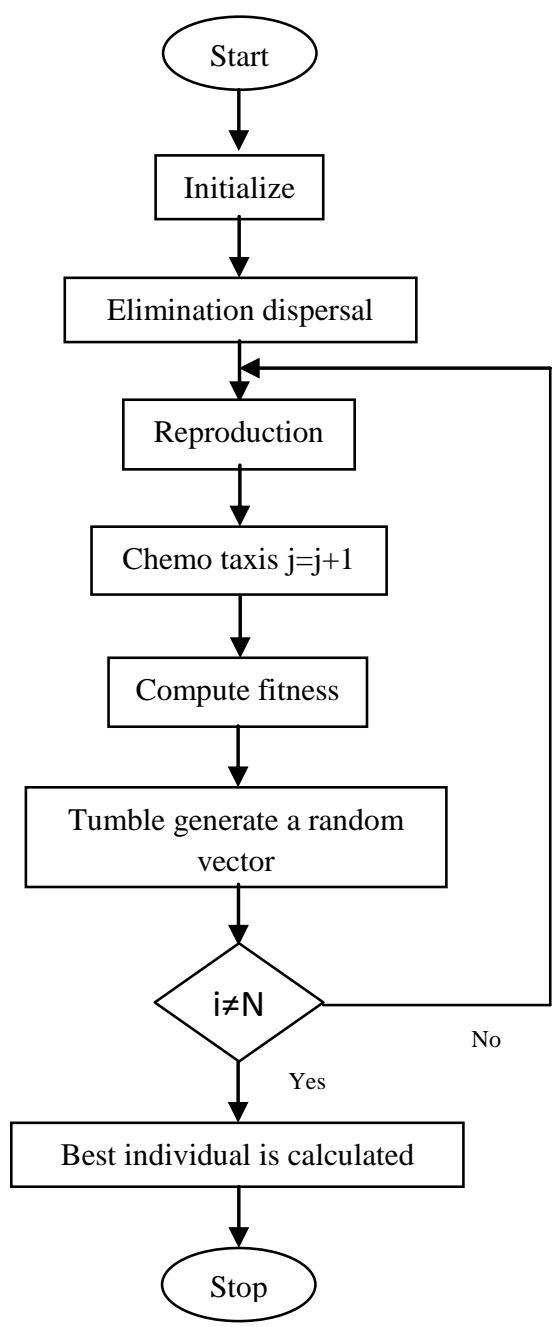

\section{RESULTS AND DISCUSSION:}

The proposed algorithm to solve the transmission network expansion planning problem bacterial foraging is applied and implemented. In order to compare the proposed bacterial foraging algorithm to the already established genetic algorithm [12] and to prove the validity of the proposed planning techniques, it was applied to the IEEE garvers 6 bus systems. The configuration of the test system before expansion is given. In order to solve the transmission network expansion planning considering network adequacy restrictions and operational cost, the proposed bacterial foraging is implemented for various missing the expanded network adequacy. The load data's is also given. A minimization of the objective function given by subject to the constraints given has been made using the nonlinear programming

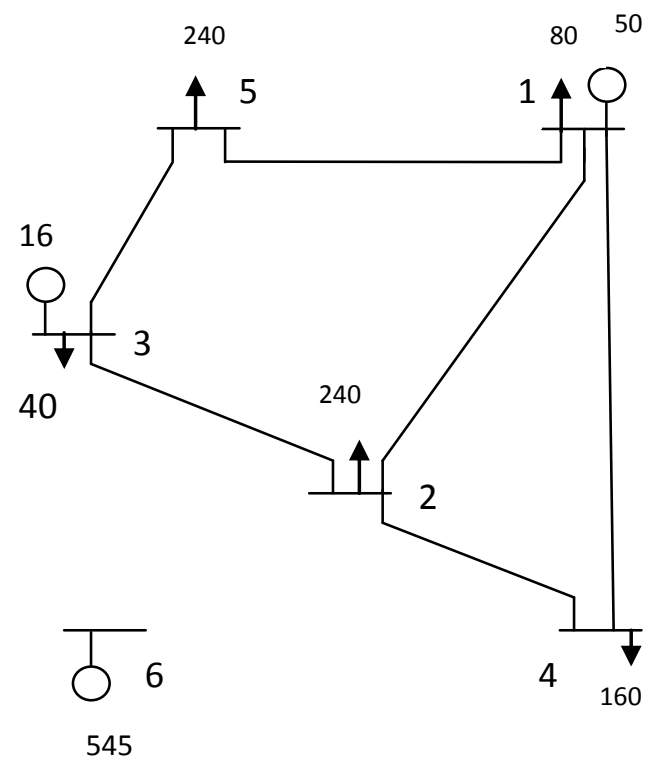

Fig 1. Garvers existing 6 bus system with existing data future load and generation.

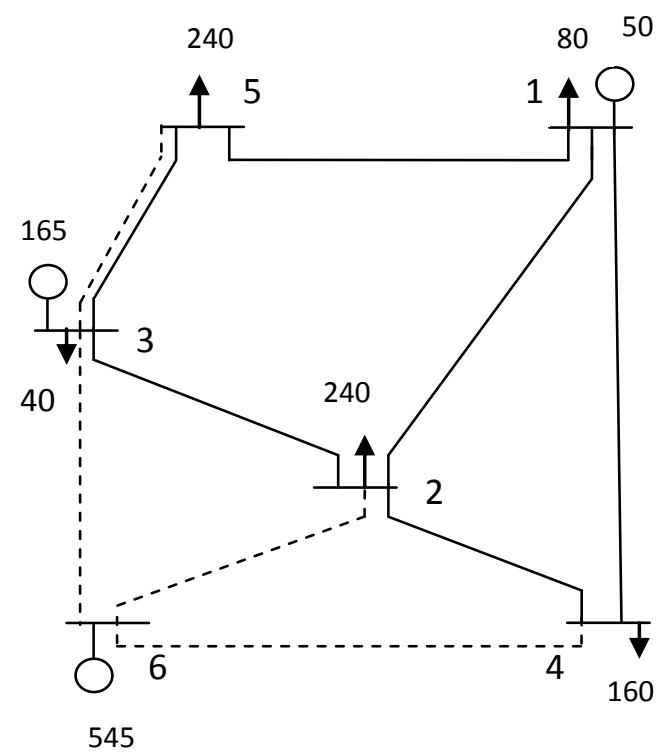

Fig 2. Network with possible routes

Table 1. CONFIGURATION OF THE NETWORK

\begin{tabular}{|c|c|c|}
\hline From bus & To bus & Length $(\mathrm{km})$ \\
\hline 1 & 2 & 40 \\
\hline 1 & 4 & 60 \\
\hline
\end{tabular}




\begin{tabular}{|l|l|l|}
\hline 1 & 5 & 20 \\
\hline 2 & 3 & 20 \\
\hline 2 & 4 & 40 \\
\hline 3 & 5 & 20 \\
\hline 6 & 2 & 30 \\
\hline 6 & 4 & 30 \\
\hline 6 & 3 & 48 \\
\hline
\end{tabular}

The power flow values obtained after the first iteration are given in table. It is clear that the route between bus 6 and bus 2 has the maximum overload. Therefore, a line is added (with a $100 \mathrm{MW}$ capacity) to this route. After this addition, the maximum overload is now shifted to the path connecting buses 6 and 4. Hence, a line is added to this path. As a result, the overload is back on the 6-2 path, which has been encountered before in this iteration.

Table 2. POWER FLOW IN THE FIRST ITERATION

\begin{tabular}{|c|c|c|}
\hline Line & Flow(MW) & Bus to bus \\
\hline 1 & 31.99 & $2-1$ \\
\hline 2 & 21.33 & $4-1$ \\
\hline 3 & 23.32 & $1-5$ \\
\hline 4 & 121.68 & $3-2$ \\
\hline 5 & 0 & $4-2$ \\
\hline 6 & 100 & $3-5$ \\
\hline$* 7$ & 259.31 & $6-2$ \\
\hline$* 8$ & 181.33 & $6-4$ \\
\hline$* 9$ & 104.35 & $6-3$ \\
\hline$* 10$ & 116.67 & $3-5$ \\
\hline
\end{tabular}

Table 3. POWER FLOW IN THE SECOND ITERATION

\begin{tabular}{|c|c|c|}
\hline Line & Flow(MW) & Bus to bus \\
\hline 1 & 32.18 & $2-1$ \\
\hline 2 & 33.41 & $4-1$ \\
\hline 3 & 35.60 & $1-5$ \\
\hline 4 & .0010 & $3-2$ \\
\hline 5 & 17.94 & $4-2$ \\
\hline 6 & 99.97 & $3-5$ \\
\hline 7 & 99.99 & $6-2$ \\
\hline 8 & 76.07 & $6-4$ \\
\hline$* 9$ & 154.23 & $6-3$ \\
\hline$* 10$ & 135.28 & $6-4$ \\
\hline$* 11$ & 79.39 & $6-3$ \\
\hline$* 12$ & 104.42 & $3-5$ \\
\hline
\end{tabular}

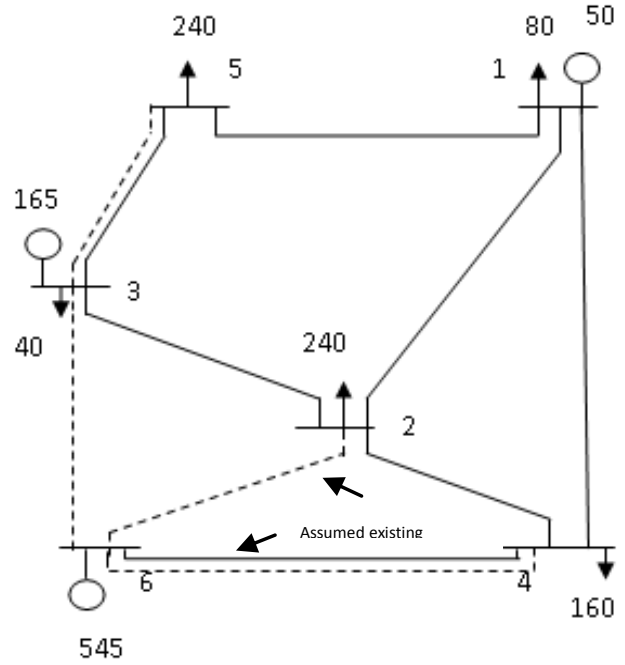

Fig 3. Two circuits added in iteration one.

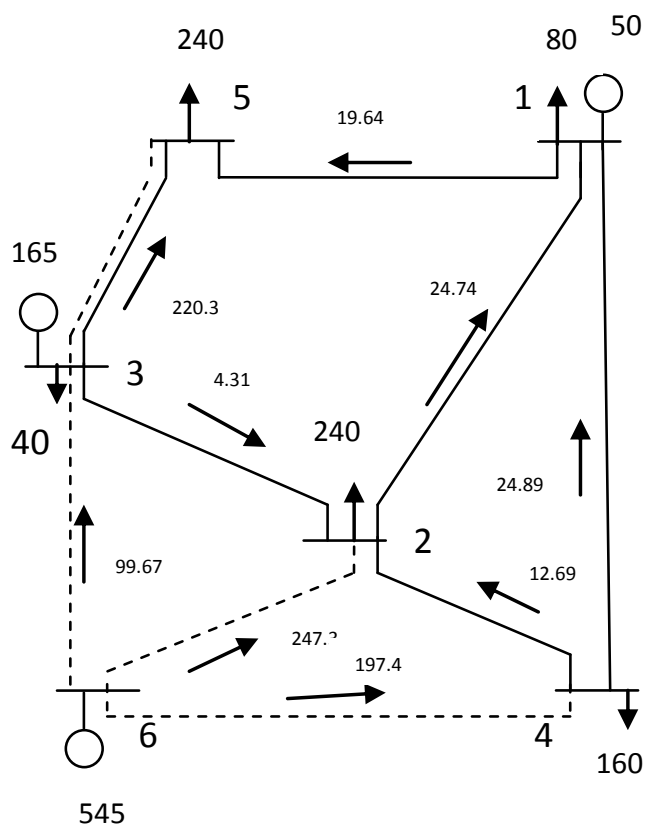

Fig 4. Final expanded network

The process of adding new lines, minimizing the objective function subject to the specified constraints is repeated until no overload exists. In order to investigate the effectiveness of the loss coefficient $\mathrm{k}$, different values are considered where the case of $\mathrm{k}=500$ is presented in detail.

The proposed bacterial foraging multi-objective transmission system planning algorithm is evaluated via computer simulation

Choice of Parameters:

- The number of bacteria, $s=25$

- Number of chemo tactic steps $\mathrm{Nc}=20$

- Limits the length of a swim $\mathrm{Ns}=4$

- The number of reproduction steps Nre=4

- The number of elimination-

- dispersal events $\mathrm{Ned}=2$ 


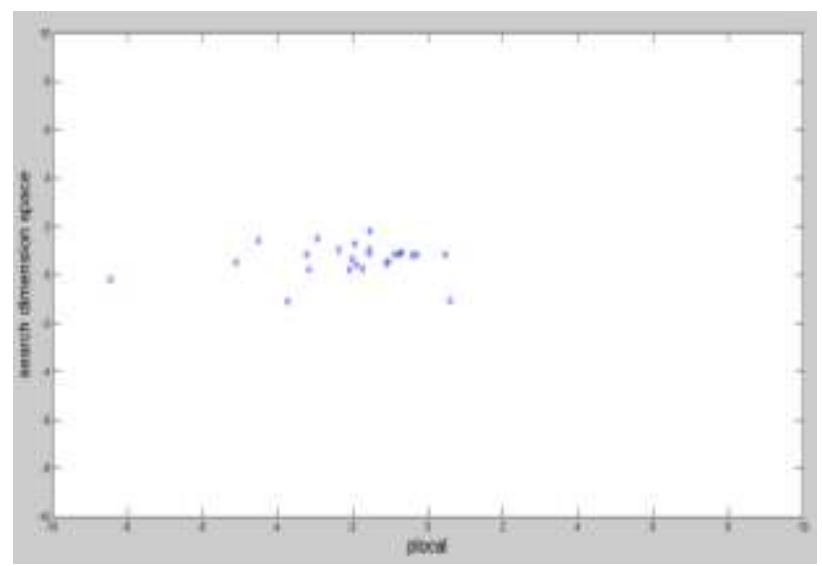

Fig 5. Searching particles during $1^{\text {st }}$ iteration

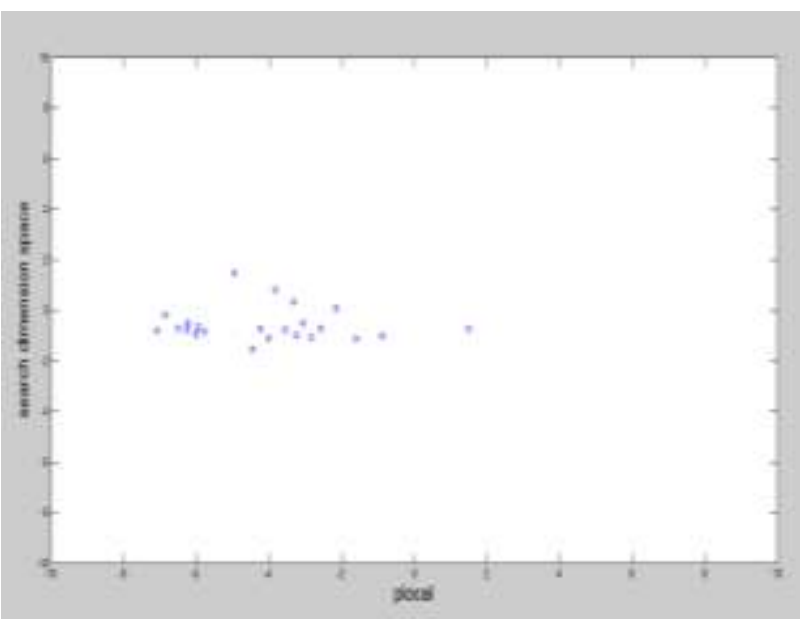

Fig 6. Searching particles during $2^{\text {nd }}$ iteration

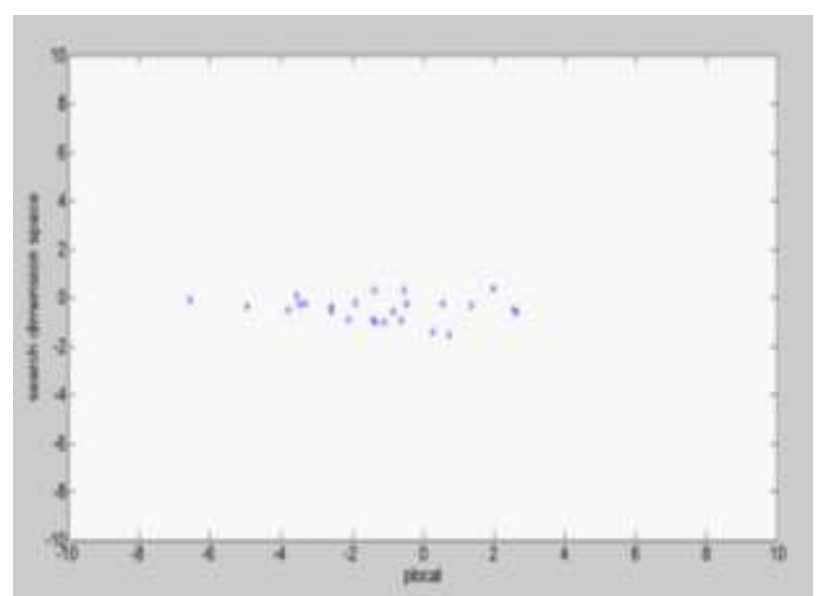

Fig 7. Particle search final iteration

At the end of iteration

pbest $=0.7699$

$$
-1.0053
$$

Increase of uncertainness demand, the network adequacy also increasing, therefore the network also expanding. meanwhile expansion cost of the network is increased. The proposed method results show that expansion cost lower. The fig.8 shows network adequacy versus network expansion cost. The optimal values of demand in each load bus are shown in table. 6

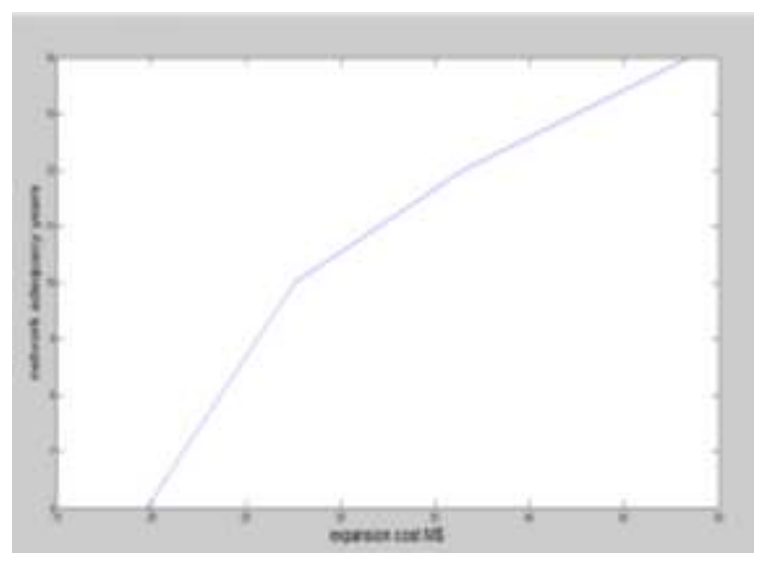

Fig 8. Adequacy curve with respect to network expansion cost

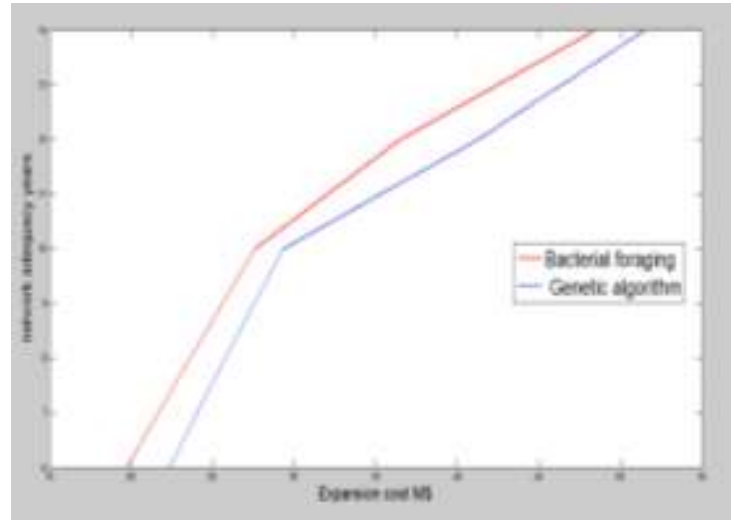

Fig 9. Comparison result

Table 4. Proposed Configuration and Cost for Network Expansion With Respect To $\mathrm{T}_{0}=8$ years

\begin{tabular}{|c|c|c|}
\hline Corridor & $\begin{array}{c}\text { Number Of } \\
\text { Required Circuits }\end{array}$ & $\begin{array}{c}\text { Expansion } \\
\text { Cost }\end{array}$ \\
\hline $2-6$ & 4 & \multirow{2}{2}{} \\
\hline $5-6$ & 1 & M\$US \\
\hline
\end{tabular}

Table 5. Proposed configuration and cost for network expansion with respect to $\mathrm{T}_{\mathrm{O}}=10$ years

\begin{tabular}{|c|c|c|}
\hline Corridor & $\begin{array}{c}\text { Number Of } \\
\text { Required } \\
\text { Circuits }\end{array}$ & $\begin{array}{c}\text { Expansion } \\
\text { Cost }\end{array}$ \\
\hline $2-6$ & 4 & \multirow{3}{*}{$\begin{array}{c}27.59 \\
\text { M\$US }\end{array}$} \\
\hline $3-5$ & 1 & \\
\hline $4-6$ & 2 & \\
\hline
\end{tabular}

Table 6. Calculated demands and optimal solution:

\begin{tabular}{|c|c|c|}
\hline Load bus & OS 1(MW) & OS 2(MW) \\
\hline 1 & 75.39 & 74.42 \\
\hline 2 & 227.16 & 219.40 \\
\hline 3 & 41.13 & 39.62 \\
\hline 4 & 146.61 & 145.13 \\
\hline 5 & 219.71 & 231.13 \\
\hline
\end{tabular}




\section{CONCLUSION}

In this paper, a new approach a modified bacterial foraging algorithm has been presented and applied to transmission network expansion planning problem for standard IEEE 6-bus system. The problem has been formulated Multiobjective optimization with operational cost and network adequacy restriction objectives. The results show that proposal approach is efficient for solving multi objective transmission network expansion planning problem. Finally, using the adequacy index on the expansion cost, an optimized plan is acquired with respectively lower expansion cost according to specified adequacy and the proposed investment of transmission network expansion planning represents further development and improvement in this work.

The results using the proposed approach compared to other techniques. It is clear that the proposed approach novel promising alternative to solve the Multi objective optimization problem and solution of transmission network expansion planning considering network adequacy restriction using bacterial foraging algorithm is shows that the expansion cost is decreased.

\section{REFERENCE}

[1] Jalilzadeh, S., Kazemi, A., Shayeghi, H., and Mahdavi, M. 2008,"Technical and economic evaluation of voltage level in transmission network expansion planning using GA", Energy conversion and Management, Vol. 49, No. 5, pp. 1119-1125.

[2] Ranjithkumar, K., Sakthibala, D., and Dr.Palaniswami, S., "Efficiency Optimization of Induction Motor Drive Using Soft Computing Techniques", International journal of computer applications, Vol.49, No.5, pp. 1179-1125.

[3] Choi, J., Mount, T., and Thomas, R. 2006,” Transmission system expansion plans in view point of deterministic probabilistic and security reliability criteria", Proc. the $39^{\text {th }} \quad$ Hawaii International Conference on System Sciences, Hawaii, Vol. 10, pp. 247b-247b.

[4] Silva, I. D. J., Rider, M. J., Romero, R., and Murari, C. A. 2005,"Transmission network expansion planning considering uncertainness in demand", Proc. IEEE Power Engineering Society, Vol. 2, pp.1424-1429.

[5] Braga, A.S.D., and Saraiva, J.T. 2005. "A multiyear dynamic approach for transmission expansion planning and long- term marginal costs computation", IEEE Trans. Power Systems, Vol. 20, No. 3, pp. 1631-1639.

[6] Geoff Leyland. 2002. A brief introduction to evolutionary algorithm and multi objective optimization.

[7] Samarakoon, H., Shrestha, R. M., and Fujiwara, O. 2001, "A mixed integer linear programming model for transmission expansion planning with generation location selection", Electrical Power and Energy Systems, Vol. 23, No. 4, pp. 285-293.

[8] Abdelaziz, A.R. 2000,"Genetic algorithm-based power transmission expansion planning", Proc. the 7th IEEE International Conference on Electronics, Circuits and Systems, Jounieh, Vol. 2, pp. 642-645.
[9] Silva, E.L., Gil, H.A., and Areiza, J.M. 2000,"Transmission network expansion planning under an improved genetic algorithm",IEEE Trans. Power Systems, Vol. 15, No. 3, pp. 1168-1174.

[10] Chanda, R. S., and Bhattacharjee, P. K.. 1998," A reliability approach to transmission expansion planning using fuzzy fault-tree model", Electric Power Systems Research, Vol. 45, No. 2 , pp. 101-108.

[11] Gallego, R.A., Monticelli, and R. Romero, 1998, "Transmission system expansion planning by an extended genetic algorithm", IEE Proc.Generation, Transmission and Distribution, Vol. 145, No. 3, pp.329-335.

[12] Gallego, R. A., Alves, A. B., Monticelli, and Romero, A. R. 1997,'Parallel simulated annealing applied to long term transmission network expansion planning", IEEE Trans. Power Systems, Vol. 12, No. 1, pp. 181-188.

[13] Ganguly, S., Sahoo, N. C., and D. Das.," Multi-Objective Planning of Electrical Distribution Systems using Particle Swarm Optimization", Department of Electrical Engineering, Indian Institute of Technology, Kharagpur.

[14] Zakariya Mahmoud Al-Hamouz., and Ali Sadiq Al- Faraj, A.,"practical method for Transmission Expansion Planning Using Nonlinear Programming".

[15] Alseddiqui, J., and Thomas, R.J. "Transmission Expansion Planning Using Multi- Objective Optimization".

[16] Panigrahi, B.K., and Ravikumar Pandi, V., "Bacterial foraging optimisation: Nelder-Mead hybrid algorithm for economic load dispatch", Department of Electrical Engineering, IIT Delhi.

[17] Heidita boada, A., Fatema baheranwala, Coid David, W., and Naruemon wattanapongsakorn,"A Practical solution for multi objective optimization: an application to system reliability design", Department of industrial and system engineering, Rutgers University, Piscataway, USA.

[18] Hans-director joos., Johann Bals., Gertjan Looye., and Klaus chnepper Andras varga,"A multi objective optimization based software environment for control systems design”,DLR-German aerospace center, webling.

[19] Mathew, M., Leenus Jehan., and Babu. B.V., "Differential evolution for multi objective optimization", Chemical enginnering department BITS, Pilani.

[20] Mantway, A. H., and Mohammad Al-Muhaini," MultiObjective BPSO Algorithm for Distribution System Expansion Planning Including Distributed Generation”.

[21] Shayeghi, H., and Mahdavi, M. "Optimization of Transmission Lines Loading in TNEP Using Decimal Codification Based GA".

[22] Russell Bent., Alan Berscheid., and Loren Toole, G. "Transmission Network Expansion Planning with Simulation Optimization". 